\title{
BILLIARDS GAMBLING IN TENGIN BARU VILLAGE, KECAMATAN SEPAKU, PENAJAM PASER UTARA DISTRICT
}

\section{PERMAINAN JUDI BILIAR DI DESA TENGIN BARU KECAMATAN SEPAKU KABUPATEN PENAJAM PASER UTARA}

\author{
Muhammad Ricky Saputra ${ }^{1}$, Lisbet Situmorang ${ }^{2}$ \\ Universitas Mulawarman, Indonesia \\ Email Correspondence: rickychalledae@ymail.com
}

\begin{abstract}
:
This article interprets the game of Billiards Gambling in Tengin Baru Village, Sepaku District, Penajam Paser Utara Regency which is done openly. The social context of the billiard gambling text can be said to be like being in a social space that is starting to open up by the influence of global economic culture, bound by the Anti-Gambling Law, average primary school education levels, the majority of followers of Islam and local tribal values that also prohibit gambling. The Billiards Gambling Game is a combination of three elements, namely: (billiard sports, playing card gambling, buying and selling games). The sport of billiards gambling is used as a mode of outer settlement, art games are used as the core of the game, and both are packaged as entertainment businesses that are subject to buying and selling games. In the players' understanding, Billiards Gambling is transformed into various meanings according to subjectivity such as: hobbies, games, challenging games, professions, entertainment, fun, official games. In the text, the readers of the Biliary Gambling game get an articulation of new meanings that are not always in line with what the original author meant.
\end{abstract}

Keywords: Billiards Gambling, Social Action, Social Context, Social Hermeneutics

\begin{abstract}
ABSTRAK:
Artikel ini menafsir permainan Judi Biliar di Desa Tengin Baru Kecamatan Sepaku Kabupaten Penajam Paser Utara yang di lakukan secara terang-terangan. Konteks sosial dari teks judi biliar ini bisa dikatakan seperti berada di ruang sosial yang mulai terbuka oleh pengaruh budaya ekonomi global, terikat oleh UU Anti Perjudian, tingkat pendidikan rata- rata sekolah dasar, mayoritas penganut islam dan nilai-nilai lokal suku yang juga melarang perjudian. Permainan Judi Biliar adalah perpaduan tiga elemen yaitu: (olahraga biliar, judi kartu remi, permainan jual beli). Olahraga judi biliar digunakan sebagai modus penapakan luar, permainan kartu remi digunakan sebagai inti permainan, dan keduanya dikemas sebagai bisnis hiburan yang tunduk pada permainan jual beli. Dalam pemahaman para pemain, Judi Biliar ini menjelma menjadi beragam makna menurut subyektifitas seperti: hobbi, game, permainan penuh tantangan, profesi, hiburan, iseng-isengan, permainan yang resmi. Di teks para pembaca permainan Judi Biliar mendapatkan artikulasi pemaknaan baru yang tidak selalu sejalan dengan apa maksud awal pengarangnya
\end{abstract}

Kata Kunci: Hermenuitik Sosial, Judi Biliar, Konteks Sosial, Tindakan Sosial

\begin{tabular}{l|l|l} 
Article Info & $:$ & January 2020 \\
\hline Received & $:$ & January 2020 \\
\hline Accepted & $:$ & January 2020 \\
\hline Published & $:$ & https://doi.org/10.30872/psd.v1i1.15 \\
\hline DOI &
\end{tabular}

Copyright and License

Authors retain copyright and grant the journal right of first publication with the work simultaneously licensed under a Creative Commons Attribution 4.0 International License that allows others to share the work with an acknowledgment of the work's authorship and initial publication in this journal. 


\section{PENDAHULUAN}

Pada hakekatnya perjudian sudah ada sejak jaman prasejarah. Perjudian seringkali dianggap seusia dengan peradaban manusia. Sejarah perjudian dapat di lihat melalui ritual-ritual religi dalam masyarakat prasejarah. Di dalamnya terdapat prosedur sederhana dimana benda-benda kecil, seperti kerikil, tongkat, kacang-kacangan, panah dan sebagainya. Di dunia barat perilaku berjudi sudah dikenal sejak jaman Yunani kuno. Para penjudi primitif adalah para dukun yang membuat ramalan ke masa depan dengan menggunakan batu, tongkat atau tulanghewan yang dilempar ke udara dan jatuh ditanah. Biasanya yang diramal pada masa itu adalah nasib seseorang pada masa mendatang.

Di dunia barat perilaku berjudi sudah dikenal sejak jaman Yunani kuno. Dari praktek divinatori masyarakat awal, alat-alat judi pun berevolusi dari benda- benda yang digunakan. Di antara bahan yang paling sering digunakan adalah gading, batu, kayu, amber hewan dan gigi manusia. Beberapa dadu berbentuk seperti piramida, tapi yang paling populer berbentuk kubus. Perkembangan perjudian di Negara-negara penjudi terbesar di dunia. Mulai dari sepakbola, kartu, hingga lotere. Lotto, kartu gosok, mesin poker, dan taruhan sepakbola adalah beberapa cara berjudi favorit yang disukai masyarakat.

Biliard yang telah dikenal baik di Eropa sejak abad 15, ternyata tidak mudah dibawa ke amerika. Selain jarak yang jauh, ongkos angkut tentu juga sangat mahal. Baru di awal abad 19 amerika mulai membuat meja Biliard. Baru di sekitar tahun 1840 biliard menjadi sangat populer. Michael Phelan, pemilik New York Billiard Parlor, sejak tahun 1850 gencar melakukan kampanye dan menyelenggarakan kompetisi hingga biliard menjadi olahraga bergengsi saat itu.

Perjudian di Indonesia sudah ada sejak zaman penjajah Belanda. Pada umumnya, dulu perjudian selalu terkait dengan dunia malam dan hiburan. judi di Indonesia sudah berkembang sangat pesat dengan banyaknya jenis-jenis perjudian yang berkembang di kalangan masyarakat Indonesia baik yang di lakukan dengan cara terang-terangan ataupun dengan cara sembunyai-sembunyi. Adapun Jenis judi yang tenar di kalangan masyarakat Indonesia: Togel, Sabung Ayam, SDSB (Sumbangan Dana Sosial Berhadiah), Judi Kartu, Judi Online. Sejarah perkembangan olahraga billiar di Indonesia pertama kali muncul dari kalangan masyarakat lapisan bawah. hal ini sangat berbeda dengan asal perjalanan billiar yang ditemukan abad ke 15 di Eropa Utara yang mengalami kemajuan pesat, sehingga menjadi kegiatan olahraga yang dilakukan oleh semua kalangan baik raja, presiden, pengusaha, dan anggota masyarakat lainnya.

Desa Tengin Baru kecamatan Sepaku Kabupaten Penajam Paser Utara yang telah berkembang disegala aspek pembangunan yang bersifat fisik dan berhubungan dengan sumber daya manusia mengandung resiko terjadinya perubahan yang meninbulkan dampak, baik yang bersifat negatif maupun positif. Munculnya rumah-rumah biliar selama ini seperti ramainya pasar. Mereka berkumpul dan menunggu giliran waktunya bermain dengan satu fokus pandangan ke meja biliar, seperti yang ada di kawasan ini yang menjadi salah satu pusat rumah-rumah Biliar

Dalam Teori Hermeneutika Sosial Paul Ricoeur yang mengatakan bahwa 'tindakan sosial sebagai sebuah teks.' Paul Ricoeur adalah seorang filsuf sekaligus teoritikus sastra yang berhasil melebarkan pengertian 'teks' bukan hanya terpaku pada tulisan baku tetapi juga tindakan bermakna. Dengan memperlakukan tindakan bermakna sebagai sebuah teks, maka interpretasi permainan judi billiar ini akan lebih menggunakan interpretasi tekstual atau kerja hermeinuitika sosial. Di sini hermeneutika berkembang menjadi teori tentang bekerjanya pemahaman dalam menafsirkan teks. Hermeneutika diartikan sebagai sebuah cara untuk memahami teks yang pada akhirnya, ujung dari proses itu adalah ditemukannya makna atau pesan. dalam olahan Paul Ricoeur, Hermeneutik bisa digunakan untuk menafsir tindakan-tindakan sosial

\subsection{Teks dan Otonomisasi Teks}

Teks adalah diskursus yang dibakukan dalam bentuk tulisan. Diskursus diartikan sebagai peristiwa bahasa atau penggunaan bahasa sebagai lawan dari sistem bahasa atau sistem kode linguistik. Diskursus menunjukkan bahasa sebagai peristiwa, bukan sebagai sistem.Pengalaman dan tindakan manusia mengandung pemaknaan linguistik, oleh karena itu keduanya merupakan diskursus. Ketika sebuah diskursus telah beralih menjadi sebuah teks, maka teks akan memiliki sifat-sifat yang sama sekali bebeda dengan diskursus atau wacana (lisan). Dengan adanya distansasi, teks menjadi bersifat otonom. Otonomisasi teks, membuat semua orang bisa menafsirkan teks baik yang tersirat maupun yang tersurat tanpa harus bertanya langsung pada pengarangnya

\subsection{Tindakan Sosial Sebagai Sebuah Teks}

Weber menjelaskan bahwa obyek kajian ilmu sosial adalah tindakan sosial atau tindakan bermakna. Penjelasanya tentang apa itu 'tindakan bermakna' membendakan tindakan sosial dari sekedar tindakan yang didorong oleh insting alamiah. Permainan judi billiard itu menjadi tindakan bermakna dan karenanya juga merupakan tindakan sosial oleh karena ia memiliki tujuan yang jelas yaitu tujuan keuntungan. 
Tindakan rasional instrumental merupakan tindakan yang dilakukan oleh seseorang dengan memperhitungkan kesesuaian antara cara yang digunakan dengan tujuan yang akan dicapai oleh sang aktor. Jelas permainan judi billiard itu bukan semata-mata tindakan atas dasar insting alamiah, karena memiliki tujuan yang sangat jelas. Menurut Weber, bahwa objek ilmu sosial adalah tindakan sosial dan hanya bisa dijelaskan dengan metode pemahaman (verstehen). Terdapat berbagai macam kecocokan antara prosedur pemahaman tindakan sosial dengan prosedur hermenuitik. bahwa objek ilmu sosial adalah tindakan sosial dan hanya bisa dijelaskan dengan metode pemahaman. Memahami tindakan atau fakta sosial, tidak bisa semata-mata percaya pada fenomenologi atau makna yang memancar di permukaan atau tersurat. Bagi hermeneutik, justru makna imanen (tersirat) adalah makna yang sesungguhnya

\subsection{Judi Biliar Sebagai Sebuah Teks}

Permainan Judi Biliar bisa dikatakan sebagai kategori tindakan rasional instrumental. Permainan ini memperhitungkan dengan tepat kesesuaian antara cara yang dipilih dengan tujuan yang hendak disasar. Permainan judi-billiard ini merupakan perpaduan kreatif antara dua tindakan sosial yang sebenarnya memiliki perbedaan yang kontras. Keduanya dipadukan dan menduduki status yang berbeda.

Namun ada perbedaan yang kontras pada keduanya terutama jika dilihat dari rasionalitas tujuan yang hendak dicapai dalam dua jenis tindakan sosial itu. Permainan judi merupakan tindakan sosial yang mementingkan tujuan-tujuan keuntungan di akhir permainan. Sedangkan olahraga Billiard adalah tindakan yang lebih berorientasi pada tujuan-tujuan sportivitas untuk menujukkan kekuatan dan kesehatan tubuh para pelakunya. Keduanya juga memiliki perbedaan dalam konteks keberterimaannya di dalam konteks budaya dominan.

Olahraga Biliar menempati status sebagai instrument atau alat, sebagai cara yang dipilih dan diperhitungkan dengan tepat dengan menyesuaikan dengan konteks-konteks sosial yang ada. Judi adalah suatu kegiatan pertaruhan untuk memperoleh keuntungan dari hasil suatu pertandingan, permainan atau kejadian yang hasilnya tidak dapat diduga sebelumnya.

Judi Biliar menjadi suatu permasalahan yang unik dan baru, yang menggabungkan suatu tindakan sosial yang di anjurkan dan tindakan sosial yang dilarang dua tindakan sosial yang sangat singkron membentuk suatu teks tindakan sosial yang baru. Dengan penampakan permainan Olahraga, para pelaku bebas melakukan taruhan-taruhan yang spekulatif untuk mendapatkan keuntungan dengan jalam pintas yang sebenarnya terlarang dalam konteks wacana dominan.

\section{METODE}

Artikel ini menggunakan metode Hermeneutik untuk mengintrepretasi. Proses pemahaman makna karya merupakan fokus Hermeneutika. Hermeneutika adalah studi pemahaman dan mengintrepretasi, kerja hermenuitik dengan demikian meliputi tiga hal, pertama interpretasi teks, konteks dan para pembaca.

\subsection{Lokasi Penelitian}

Lokasi penelitian yang saya pilih adalah rumah Biliar, yang terletak di jalan Negara Km 35, Desa Tengin Baru, Kecamatan Sepaku. Daerah tersebut terletak dekat dengan Sekolah Menengah Atas (SMA) dan dekat dengan lokasi industri perkebunan kelapa sawit sehingga tempat ini kerap menjadi buah bibir masyarakat.

\subsection{Metode Pengmpulan Data}

Pengamatan dan Pencatatan Digunakan untuk mendeskripsikan teks permainan Judi Biliar. Pada tahapan ini saya akan melakukan pengamatan dan pencatatan rinci tentang proses permainan judi biliar. Pengamatan dan pencatatan tidak hanya dilakukan pada satu kali permainan berlangsung namun berkali-kali. Hal ini dilakukan untuk memastikan adanya kesamaan-kesamaan, ketidak samaan, pengembangan permianan atau punpergeseran-pergeseran permainan untuk mensiasati konteks sosial tertentu.

Wawancara Mendalam Dilakukan terutama untuk menjaring data tentang tafsir para pelaku Judi Biliar. Tahapan ini akan mengorek keterangan para pelaku Judi Biliar, bagaimana mereka menginterpretasi Judi Biliar menurut logika dan pengalamannya masing-masing.

Dokumentasi Dilakukan pada pelaksanaan penelitian di lapangan. Alat- alat seperti kamera,rekaman dan hendycam, digunakan sebagai bantuan alat dokumentasi untuk membantu menggambarkan detail datadata yang mungkin terlewat dideskripsikan oleh kata-kata. Dokumen foto atau video akan menjadi semacam 'saksi' dan 'bukti' dari fenomena yang akan saya gambarkan dalam penelitian ini. 


\subsection{Metode Interpretasi Data}

Interpretasi teks ini digunakan untuk menginterpretasi bagaimana bangunan teks Judi Biliar ini Terbentuk. Interpretasi konteks ini akan mendeskripsikan tentang nilai-nilai sosial macam apa yang berlaku di tengah masyarakat di mana permainan Judi Biliar berlangsung. Interpretasi para pembaca ini akan menginterpretasikan tafsir dari para pemain Judi Biliar sebagai para pembaca yang menafsir permainan ini menurut logika mereka masing-masing

\section{HASIL DAN PEMBAHASAN}

Tafsir Spesial Permainan Judi Biliar Daerah ini bisa dikatakan sebagai daerah yang terpencil karena letak daerahnya jauh dari pusat pemerintahan. Selama satu minggu saya menyamar sebagai pengguna jasa Judi Biliar, sebagai bagian dari pemain rutin. Saya membaur dan menjadi bagian dari komunitas Judi Biliar ini, berteman/bergaul dengan pemilik dan para pengguna jasa, serta melakukan wawancara mendalam dengan tokoh dan masyarakat awam di sekitarnya.

Saya menyaksikan bahwa Judi Biliar adalah sebuah permaianan penuh intrik untuk membungkus perjudian agar tampak sebagai permainan olahraga. Dengan menggunakan teori Hermeneutik sosial Paul Ricouer, saya bisa memahami bahwa Judi Biliar adalah sebuah teks permainan baru yang dikreasikan untuk menyiasati sebuah konteks sosial dengan berisi nilai-nilai spiritual tertentu yang dianggap tidak bisa menerima permainan ini.

\subsection{Konteks Sosial Permainan Judi Biliar}

Permianan sosial tidak pernah berlangsung dalam ruang hampa sosial. Ia berlangsung dalam sebuah ruang sosial yang syarat nilai. Kadang-kadang sebuah permianan sosial dibangun tidak melulu demi permainan itu sendiri, tetapi juga demi menyesuaikan denngan nilai-nilai yang berlaku dalam konteks sosial di mana permainan akan diselenggarakan. Saya menyaksikan adanya karakteristik yang cukup unik atas konteks sosial di mana permainan judi biliar ini berlangsung. Konteks sosial dari teks judi biliar ini bisa dikatakan seperti berada di ruang sosial perpaduan antara ruang sosial yang mulai terbuka oleh pengaruh budaya ekonomi global, tingkat pendidikan masyarakat yang beranjak meningkat berpadu dengan nilai-nilai religious yang mayoritas penganut islam dan nilai-nilai lokal suku di mana mayoritas penduduk daerah ini berasal.

Judi Biliar ini ada seiring dengan berkembangnya daerah desa ini dengan di tunjang perusahaanperusahaan perkebunan. Dengan perkembangan yang begitu pesat membuat terbukanya akses wilayah ini ke dunia luar. Dengan di bukanya perkebunan, dan para pegawai perkebunan yang membutuhkan tempattempat hiburan, membuat sebuah inspirasi bisnis yang muncul dari seseorang pebisnis yang merupakan penduduk luar yang melihat para karyawan perkebunan dan lingkungan daerah industri sebagai peluang bisnis Judi Biliar.

Bahwa judi biliar ini adalah bisnis para para pemodal cina yang meyewakan meja biliar dan perlengakapnnya untuk menarik keuntungan dari para pendatang yg menjadi pekerja perkebunan. lalu masyarakat lokal ada yg mulai ikut-ikutan mencoba permainan Judi Biliar ini. Sekali bermain membuat setagihan buat mencoba lagi sehingga membuat ketagihan beberapa orang penduduk asli kampung sini. Membuat daya tarik tersendiri rumah biliar ini untuk ramai di kunjungi para pemain. Pada titik itu pula konteks sosial lokasi ini mulai bersentuhan denngan nilai-nilai budaya luar yang lebih modern dalam hal penampilan (olahraga), namun juga klasik dalam hal isi (judi), bercampur aduk dengan kepentingan para pemodal luar yang ingin meraup keuntungan dari situasi ini.

Kehidupan beragama islam sangat kental, ajaran-ajaran dalam menjalankan kehidupan pun banyak yang masih menjaga budaya kehidupan para Nabi. Alquran pun menjelaskan dalam isinya bahwa mengharamkan dan melarang tindakan "perjudian". Penduduk dengan mayoritas beragama muslim membuat banyak berdiri bangunan Masjid dan Musolla.

Saya memperhatikan, bahwa saat ini masyarakat yang memeluk agama islam cenderung cuek dengan lingkungan sekitarnya, selama apa yang ada di lingkungannya tidak meresahkan dan tidak terlalu keluar dari aturan agama.

Tidak ada persisnya adat yang menonjol. Tidak ada ikatan aturan adat bagi masyarakat di sini untuk mematuhi batasan-batasan perbuatan dan tingkah laku di dalam bermasyarakat. Ternyata di sisi lain dari tidak adanya aturan adat yang berat, membuat para pemain Judi Biliar pun tak kalah cerdiknya dalam melakukan tindakan yang menyimpang. Judi Biliar memanfaatkan ruang yang kosong dalam daerah yang aturan-aturan adatnya tidak ketat dan cenderung tidak ada hal yang membuat Judi Biliar ini dilarang oleh adat. 
Dalam undang-undang sudah jelas menyebutkan secara rinci dalam undang-undang No. 7 Tahun 1974 (UU No.7/ 1974) tentang Penertiban Perjudian dan Peraturan Pemerintah No. 9 Tahun 1981(PP No.9/ 1981) tentang Pelaksanaan Penertiban Perjudian.

Di desa ini terdapat satu markas satuan kepolisian (polsek). Yang merupakan satuan yang berperan khusus dalam menjalankan aturan perundang- undangan. Termasuk memberantas segala bentuk perjudian, dan termasuk di dalamnya permainan Judi Biliar. yang merupakan kreasi baru yang di bungkus rapi dalam permainan sehingga tidak tampak bahwa itu perbuatan judi.

\subsection{Teks Judi Biliar}

Teks Judi Biliar merupakan gabungan dari teks-teks atau intertekstualitas (Julia Kristeva: Teeuw, 1984:145) dari beberapa teks yang berbeda. Setidaknya ada tiga elemen besar yang menjadi elemen-elemen pembentuknya. Elemen pertama yaitu Bentuk permainan Biliar dari alat yang di gunakan, aturan permainan dri awal hingga akhir. Elemen kedua adalah gaya dan cara permainan kartu remi membuat semakin klop permainan Judi Biliar. Dan elemen ketiga adalah bayaran yang menjadi klimaks suatu pertandingan dan paling tidak tampak selama pertandingan berlangsung.

Penampakan permainan olahraga biliar mendominasi penampakan luar permainan judi ini. Atribut dan proses permianan didominasi oleh penampakan pertandingan olah raga biliar. Namun di sela-sela jalannya permainan, ada sejumlah potongan-potongan dari teks-teks permainan judi yang dijadikan sebagai bagian proses permainan.

Dari adanya bentuk bangunan rumah biliar, merujuk kepada pengalaman dan tindakan manusia yang akan di tafsirkan. Mengindikasikan adanya pemusatan hubungan antara pengalaman dan tindakan yang hendak dipahami. Dengan kata lain, pengalaman dan tindakan sebagai diskursus.

Ruang interior adalah seluruh desain ruangan dan perlengkapan yang tersedia di dalam ruang bangunan. Selain di pergunakan sebagi rumah biliar, bangunan ini merupakan rumah tempat tinggal si pemilik, dengan terlihat banyak bagian-bagian khusus pribadi pemilik dan keluarganya.

Selama satu minggu penuh saya melakukan pengamatan terhadap belangsungnya permainan judi biliar ini. Saya menyaksikan berbagai macam karakter konteks sosial, teks permainan dan para pembacanya, saling berjalin dan mewarnai dengan cara yang unik. Bab ini akan mengurai bagaimana sebuah teks tentang permainan judi dibungkus sedemikian rupa menyerupai teks permainan olahraga, agar tampak tidak melawan nilai-nilai yang masih diikuti dalam konteks sosial di mana permainan dilakukan.

Perlengkapan atau atribut permainan judi biliar terdiri dari elemen-elemen perlengkapan olahraga biliar, elemen permainan judi kartu Remi dan uang. Ketiganya menempati porsi yang berbeda dalam permainan. Elemen pertama dari perlengkapan permainan judi biliar ini adalah perlengkapan olahraga Biliar. Alat-alat yang di gunakan dalam permainan Biliar umumnya dalam kejuaraan-kejuaran nasional dan internasional sama dengan alat- alat yang di gunakan dalam permainan Judi Biliar, namun dengan ukuran yang lebih kecil. Menurut penuturan informan ini, membuktikan jelas bahwa permainan dengan menggunakan kartu lebih memiliki daya tarik dan tantangan tersendiri bagi para pemain. Permainan menggunakan bola 1 sampai dengan bola 13. bola 14 dan 15 harus disisihkan karena secara nominal jumlah kartu adalah 13 untuk kartu JQK dari bola 11, 12, 13. Sedangkan Ace mewakili bola 1. Kartu remi adalah sekumpulan kartu seukuran tangan yang masing-masing kartu menunjukkan angka-angka tertentu saling berbeda satu dengan yang lainnya. Kartu yang di pegang pemain merupakan kartu rahasia, tidak boleh terlihat oleh lawan/musuh dan begitu sebaliknya, pemain tidak boleh melihat kartu pemain lain, hal tersebut bertujuan agar bola yang akan di masukkan tidak sama dengan bola yang ingin di masukkan oleh pemain lain sehingga pemain lain merasa teruntungkan. Kartulah yang menentukan kemenangan seorang pemain. 'Bayaran' adalah istilah yang digunakan para peserta untuk sebuah tindakan membayar taruhan konsekuensi dari kekalahan seseorang. Siapa yang kalah, ia harus membayar sebesar harga taruhan yang telah disepakati. Saya melihat jelas dengan pembuktian bahwa permainan olah raga ini berakhir dengan adanya judi di akhir pertandingannya. Pemaian yang kalah memberi bayaran ke pemenang dengan cara meletakkan bayaran di atas meja biliar, dan secara langsung pemain yang menang akan mengumpulkan semua bayaran yang ada di atas meja.

\subsection{Para Pembaca}

Para pembaca menafsir teks tindaan sosial sesuai dengan sudut pandang, pola pikir, pengalaman dan koleksi pengetahuan yang dimilikinya. Dalam hal ini ada ruang di mana para pembaca bisa menggunakan logika dan subyektivitasnya dalam memaknai obyek-obyek. Setiap orang bebas melakukan pemaknaan dengan logikanya. Sehingga pemaknaan menjadi sangat beragam. Walaupun saya memiliki pengalaman yang sangat subyektif, tetapi tidak ada bahasa yang bisa persis menyampaikan pemahaman saya. Setiap orang bebas memaknai, tetapi tidak bisa sama sekali keluar dari bahasa yang membentuk wacana. Maka kebebasan memaknai dibatasi oleh kendala bahasa yang tidak pernah mencukupi pemaknaan yang hendak disampaikan.

Progress in Social Development: Volume 1 No 1 Januari 2020 
Menurut keterangan informan yang saya pilih, semuanya berpendidikan terakhir Sekolah Menengan Atas (SMA). Para pemain judi biliar mayoritas beragama islam, termasuk keterangan informan yang saya pilih sebagai sumber informasi. Saya melihat latar belakang suku para pemain yang berbeda-beda, dengan memperhatikan logat bahasa yang mereka ucapkan dalam berinteraksi antara pemain. Saya juga menggali informasi tentang profesi para pemain dan terutama para informan, latar belakang profesi para informan sangat beragam ada yang bekerja sebagai pegawai negri sipil, ada yang sebagai karyawan swasta, pegawai honorer, dan ada pula pengangguran.

Kemudian membentuk pemaknaan yang bermacam-macam terhadap Judi Biliar, walaupun dengan permainan yang sama di tempat yang sama tetapi mereka punya pemaknaan masing-masing. Judi Biliar adalah tempat hiburan yang lagi ramai, membuat daya tarik tersendiri dalam mengisi waktu luang. Setelah bermain Judi Biliar banyak hal positif yang ia rasakan dalam dirinya. Ia merasa badannya semakin sehat setiap kali bermain Judi Biliar dan ia merasa mendapatkan kesenangan hati yang dapat menutupi masalah dalam rutinitasnya. Hal ini yang membuat Judi Biliar mempunyai nilai tambah baginya.

Setelah bermain Judi Biliar banyak hal positif yang ia rasakan dalam dirinya. Ia merasa badannya semakin sehat setiap kali bermain Judi Biliar dan ia merasa mendapatkan kesenangan hati yang dapat menutupi masalah dalam rutinitasnya. Hal ini yang membuat Judi Biliar mempunyai nilai tambah baginya.

Seorang pemain Judi Biliar yang cukup sering tampil dalam permainan Judi Biliar. Ia selalu meyakinkan saya bahwa bermain Judi Biliar itu merupakan permainan yang sangat mengasikkan dan membuat orang akan terus mencoba bermain berulang-ulang lagi. Ia juga meyakinkan saya di dalam wawancara, bahwa ia bermain Judi Biliar dalam permainan yang resmi.

Merupakan salah satu pecinta Judi Biliar. Awalnya ia ini merupakan karyawan swasta yang dahulunya merupakan orang yang tinggal di Perkotaan yang sangat kental dengan tempat-tempat hiburang yang ber macam-macam. Salah satunya tempat Biliar yang mengenalkannya dengan permainan Biliar. Pengalamannya memupuk kecintaannya dalam olah raga ini, sehingga membuat Biliar ini menjadi hobinya dalam memilih permainan olahraga. Ia tidak masalah dengan biaya yang di keluarkan dalam sekali bermain, dia juga tidak memikirkan untung dan ruginya dalam bermain, namun ia menegaskan bahwa yang terpenting hobinya bermain Judi Biliar tersalurkan.

Judi Biliar sebagai "Permainan yang menghasilkan uang". ia tampak sebagai pribadi yang cukup lepas, lepas dalam artian tidak terlalu mempedulikan keluarga dan lingkungan sekitarnya. Ia pun tidak peduli dengan lingkungan sekitar tentang dirinya yang menjadikan Judi Biliar sebagai kerjaan barunya. Hingga terkenal sebagai "raja bola putih", gelar ini ia dapatkan karena sering memenangkan pertandingan. Keputusan bermain Judi Biliar sebagai bagian tujuan mencari keuntungan bagi dirinya dalam mencarai uang.

Tertantang untuk bisa ikut langsung merasakan bermain Judi Biliar dari pada hanya sekedar menonton dengan duduk manis di kursi yang di sediakan. Bermain Judi Biliar memberi pemaknaan tersendiri baginya. Baginya bermain penuh tantangan itu sesuatu hal yang membuat ia bisa bermain dengan hati-hati sekaligus mengasah kemampunya untuk bermain lebih bisa dan pandai lagi dalam bermain Judi Biliar. uang yang telah di sediakan juga membuat keyakinannya semakin bertambah.

Pada tahapan teks Judi Biliar bagi para pembacanya. Para pemain memahami Permainan Judi Biliar menurut kompleks pengalaman hidup yang membangun pengelaman mereka masing-masing. Permainan Judi Biliar dibaca dari sudut pandang yang beragam, tergantung dari subyektivitas para pemainnya. Di teks para pembaca ini permainan Judi Biliar mendapatkan artikulasi pemaknaan baru yang tidak selalu sejalan dengan apa maksud awal pengarangnya.

\section{KESIMPULAN}

Perjudian sudah ada sejak jaman prasejarah. Perjudian seringkali dianggap seusia dengan peradaban manusia. Di dunia barat perilaku berjudi sudah dikenal sejak jaman Yunani kuno. Dari praktek divinatori masyarakat awal, alat- alat judi pun berevolusi dari benda-benda yang digunakan.

Perjudian di Indonesia sudah ada sejak zaman penjajah Belanda. Judi di Indonesia sudah berkembang sangat pesat dengan banyaknya jenis-jenis perjudian yang berkembang di kalangan masyarakat Indonesia baik yang di lakukan dengan cara terang-terangan ataupun dengan cara sembunyai-sembunyi. Adapun Jenis judi yang tenar di kalangan masyarakat Indonesia: Togel, Sabung Ayam, SDSB (Sumbangan Dana Sosial Berhadiah), Judi Kartu, Judi Online.

Saya membaur dan menjadi bagian dari komunitas Judi Biliar ini. Saya menyaksikan bahwa Judi Biliar adalah sebuah permaianan penuh intrik untuk membungkus perjudian agar tampak sebagai permainan olahraga. Bahwa Judi Biliar adalah sebuah teks permainan baru yang dikreasikan untuk menyiasati sebuah konteks sosial dengan berisi nilai-nilai spiritual tertentu yang dianggap tidak bisa menerima permainan ini. Konteks sosial dari teks judi biliar bisa dikatakan seperti berada di ruang sosial perpaduan antara ruang sosial yang mulai terbuka oleh pengaruh budaya ekonomi global, tingkat pendidikan masyarakat yang beranjak 
meningkat berpadu dengan nilai-nilai religious yang mayoritas penganut islam dan nilai-nilai lokal suku di mana mayoritas penduduk daerah ini berasal.

Ada tiga Teks elemen besar yang menjadi elemen-elemen pembentuk Teks Judi Biliar. Elemen pertama yaitu Bentuk permainan Biliar dari alat yang di gunakan. Elemen kedua adalah gaya dan cara permainan kartu remi. Dan elemen ketiga adalah bayaran yang menjadi klimaks suatu pertandingan. Membentuk pemaknaan yang bermacam-macam terhadap Judi Biliar, walaupun dengan permainan yang sama di tempat yang sama tetapi mereka punya pemaknaan masing-masing. Ragam tanggapan para pembaca Seperti ini: hobbi, permainan yang resmi, game (mainan), profesi, hiburan, permainan penuh tantangan dan isengisengan.

\section{DAFTAR PUSTAKA}

Deaux, K.1993. Reconstructing social identity. Person-ality and Social Psychology Bulletin, 19, 4-12.

Johnson, Doyle Paul. 1994. Teori Sosiologi: Klasik dan Moderen. Jakarta: PT Gramedia Pustaka Utama.

Kartono, Kartini. 2005. Patologi Sosial. Jakarta: Raja Grafindo Persada.

Mutiara, Dalia. 1962. Tafsiran Kitab Undang-undang Hukum Pidana. Jakarta: Ghalia Indonesia.

Poerwadarminta. 1995. Kamus Besar Bahasa Indonesia. Jakarta: Gramedia. Ricoeur, Paul. 2006. Hermeneutika Ilmu Sosial. Yogyakarta: Kreasi Wacana Yogyakarta.

Richard, E. Palmer. 2003.Hermeneutics Interpretation Theory in Schleirmacher, Dilthey, and Gadamer, Terj:

Hermeunitika; Teori Baru Mengenai Interpretasi. Yogyakarta: Pustaka Pelajar.

Simorangkir, J. 1990. Pelajaran Hukum Indonesia. Jakarta: Gunung Agung. Soesilo, R. 1996. Kitab Undang-Undang Hukum Pidana (KUHP), Bogor: Politea.

\section{UNDANG-UNDANG REPUBLIK INDONESIA NOMOR 7 TAHUN 1974 TENTANG PENERTIBAN PERJUDIAN UNDANG-UNDANG HUKUM PIDANA PASAL 303 AYAT (1), (2) DAN (3).}

Kabar Masa Silam. 2012. Menyingkap Sejarah Perjudian Masyarakat Dunia.

http://kabarmasasilam.blogspot.com/2012/11/manyingkap-sejarah- perjudian-masyarakat.html (diakses pada 1 maret 2013).

Wakmintogel, (2011, 22 januari). Sejarah Perjudian Negara. http://wakmintogel.wordpress.com/2011/01/22/sejarahperjudian-negara/ (di aksespada 1 maret 2013).

Syahid Latif. 2011. Negara-negara penjudi Terbesar di Dunia. http://sepuluhbesardijagadraya.blogspot.com/2012/05/negara-penjudi- terbesar-di-dunia.html (di akses pada 2 maret 2013).

Kisah Bersejarah. $\quad 1620 . \quad$ Sejarah $\quad$ Masyarakat $\quad$ Dan $\quad$ Judi. http://bataviadigital.pnri.go.id/kisah/?box=detail\&id_record=22\&npage=2

\&search_key=\&search_val=\&status_key=\&dpage=1 (di akses pada 03 maret 2013).

Johanes Papu. 2002. Sejarah Dan Jenis Perjudian.

http://www.e-psikologi.com/epsi/sosial_detail.asp?id=279 (di askes pada 8 maret 2013).

Hanggar Billiard Jakarta. 2010. Sejarah Dan Perkembangan Olahraga Biliar. http://hanggarbilliardjkt.blogspot.com/2010/03/sejarah-dan- perkembangan-olahraga.html (di akses pada tanggal 10 maret 2013).

Luxboy. 2009. Sejarah Billiard di Amerika.

http://rifkikousten.blogspot.com/ (di akses pada tanggal 10 maret 2013).

Kidyoti. 2003. Sejarah Perjudian. http://www.gogle.com ( di akses 25 maret 2013).

Menurut Cohan. 1964. Sejarah Gambling. http://kelompokeptiklima.wordpress.com/2013/04/29/sejarah-gambling/ (di akses pada 02 juni 2013).

http://id.wikipedia.org/wiki/Biliar (diakses pada 12 juni 2013). 